\title{
Experimental study on the electrical conductivity of quartz andesite at high temperature and high pressure: evidence of grain boundary transport
}

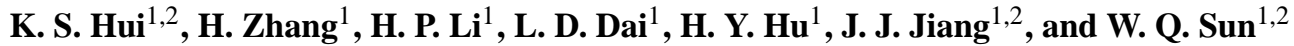 \\ ${ }^{1}$ Key Laboratory of High-Temperature and High-Pressure Study of the Earth's Interior, Institute of Geochemistry, \\ Chinese Academy of Sciences, Guiyang, Guizhou 550002, China \\ ${ }^{2}$ University of Chinese Academy of Sciences, Beijing 100049, China
}

Correspondence to: L. D. Dai (dailidong_2014@hotmail.com)

Received: 5 April 2015 - Published in Solid Earth Discuss.: 6 May 2015

Revised: 23 August 2015 - Accepted: 25 August 2015 - Published: 2 September 2015

\begin{abstract}
In this study, the electrical conductivity of quartz andesite was measured in situ under conditions of 0.5 $2.0 \mathrm{GPa}$ and $723-973 \mathrm{~K}$ using a YJ-3000t multi-anvil press and a Solartron-1260 Impedance/Gain-Phase Analyzer. Experimental results indicate that grain interior transport controls the higher frequencies $\left(10^{2}-10^{6} \mathrm{~Hz}\right)$, whereas the grain boundary process dominates the lower frequencies $\left(10^{-1}\right.$ $10^{2} \mathrm{~Hz}$ ). For a given pressure and temperature range, the relationship between $\log \sigma$ and $T^{-1}$ follows the Arrhenius relation. As temperature increased, both the grain boundary and grain interior conductivities of quartz andesite increased; however, with increasing pressure, both the grain boundary and grain interior conductivities of the sample decreased. By the virtue of the dependence of grain boundary conductivity on pressure, the activation enthalpy and the activation volume were calculated to be $0.87-0.92 \mathrm{eV}$ and $0.56 \pm 0.52 \mathrm{~cm}^{3} \mathrm{~mol}^{-1}$, respectively. The small polaron conduction mechanism for grain interior process and the ion conduction mechanism for grain boundary process are also discussed.
\end{abstract}

\section{Introduction}

Studies of the electrical conductivity of rocks at high temperatures and high pressures have found that similar to temperature and pressure, grain boundary greatly affects the electrical properties of rocks. Grain boundary, a general property of rocks, is therefore receiving increasing attention from researchers. Peridotite is the most important rock in the upper mantle, and the influence of grain boundary on its electrical conductivity has been studied in detail (Tyburczy and Roberts, 1990; Roberts and Tyburczy, 1991, 1993, 1994; Xu et al., 1998, 2000; ten Grotenhuis et al., 2004; Watson et al., 2010; Wu et al., 2010). However, the relation between the total conductivity, grain boundary and grain interior conductivity for andesite remains unclear till now.

Andesite forms in plate subduction settings, and is thus widely distributed in the orogenic belts bordering the Pacific Ocean. Extensive studies of its electrical conductivity have achieved notable results. Waff and Weill (1975) measured the electrical conductivities of andesite of varying components $\left(\mathrm{Na}_{2} \mathrm{O}\right.$ : 4.96-7.83 wt \%; FeO: 4.99-13.7 wt \%) using a direct current (DC) method at room pressure and different oxygen partial pressures of $\mathrm{CO}_{2}$ and $\mathrm{H}_{2}$. They found that increasing alkali ion content significantly increased the electrical conductivity of andesite, whereas oxygen fugacity and iron content had little effect (Waff and Weill, 1975). Tyburczy and Waff (1983) employed the alternating current (AC) at pressures of $0-2.55 \mathrm{GPa}$ and temperatures of $1473-1673 \mathrm{~K}$ to observe the electrical conductivity of andesite melt from Crater Lake. By combining the electrical conductivity data from andesite melt and tholeiite to model the high conductivity zone, they concluded that the electrical conductivity of andesite melts increases with the rise of pressure, and that a minimum melt fraction of 5-10\% can account for the anomalously high electrical conductivity of the upper mantle in typical andesite regions (Tyburczy and Waff, 1983). 
Table 1. Whole rock analysis by X-ray fluorescence (XRF) and chemical composition of dominant minerals for quartz andesite by the electron microprobe (EPMA).

\begin{tabular}{lrrrr}
\hline Oxides & $\begin{array}{r}\text { XRF for whole } \\
\text { rock (wt \%) }\end{array}$ & $\begin{array}{r}\text { EPMA for } \\
\text { anorthoclase }(\text { wt } \%)\end{array}$ & $\begin{array}{r}\text { EPMA for } \\
\text { albite }(w t \%)\end{array}$ & $\begin{array}{r}\text { EPMA for } \\
\text { amphibole (wt \%) }\end{array}$ \\
\hline $\mathrm{SiO}_{2}$ & 66.47 & 59.56 & 65.25 & 52.47 \\
$\mathrm{Al}_{2} \mathrm{O}_{3}$ & 13.57 & 26.20 & 19.75 & 3.61 \\
$\mathrm{MgO}$ & 0.44 & 0.15 & 0.03 & 15.72 \\
$\mathrm{CaO}$ & 1.12 & 2.28 & 0.62 & 12.18 \\
$\mathrm{Na}_{2} \mathrm{O}$ & 4.98 & 6.99 & 10.55 & 0.20 \\
$\mathrm{~K}_{2} \mathrm{O}$ & 4.16 & 3.09 & 0.02 & 0.18 \\
$\mathrm{FeO}$ & 5.02 & 0.90 & 1.03 & 11.23 \\
$\mathrm{TiO}_{2}$ & 0.22 & 0.03 & 0.01 & 0.33 \\
$\mathrm{Cr}_{2} \mathrm{O}_{3}$ & 0.02 & 0.02 & 1.47 & 0.03 \\
$\mathrm{MnO}_{2}$ & - & 0.04 & 0.00 & 0.12 \\
$\mathrm{P}_{2} \mathrm{O}_{5}$ & 0.81 & - & - & - \\
$\mathrm{L.O.I}$ & 2.74 & - & - & 96.07 \\
\hline Total & 99.55 & 99.26 & 98.73 & - \\
\hline
\end{tabular}

More recently, Laumonier et al. (2015) measured the electrical conductivity of dacitic melts with $\mathrm{H}_{2} \mathrm{O}$ contents up to $12 \mathrm{wt} \%$ at pressures of $0.15-3.0 \mathrm{GPa}$ and temperatures of $673-1573 \mathrm{~K}$, and demonstrated that the electrical conductivity is strongly dependent on the water content. Likewise, the influence of pressure on the activation enthalpy is strongly correlated with the sample's water content. By means of $T-$ $P-\mathrm{H}_{2} \mathrm{O}$ model (temperature-pressure- $\mathrm{H}_{2} \mathrm{O}$ model), crustal and mantle wedge conductive bodies have been interpreted by the presence of silica-rich, hydrous, partially crystallized magma (Laumonier et al., 2015). However, previous studies mainly focused on the grain interior conductivity of andesite rather than the effect of grain boundary conductivity.

In this study, the grain boundary electrical conductivity of quartz andesite was measured at pressures of $0.5-2.0 \mathrm{GPa}$ and temperatures of 723-973 K within the frequency range of $10^{-1}$ to $10^{6} \mathrm{~Hz}$. The characteristic parameters of the electrical conductivity of quartz andesite acquired here include the activation enthalpy and the activation volume. These parameters allow for discussion of the relationship between the contributions from the grain interior and grain boundary conductivity, and the total conductivity. The conduction mechanism was also discussed.

\section{Experimental procedure}

\subsection{Sample preparation}

Quartz andesite was collected from Shizhu Town, Yongkang City, Zhejiang Province, China. The samples were fresh and unaltered, and appeared pale-yellow in color. According to observation under the optical microscope, the quartz andesite mainly consists of fine-grained plagioclase, amphi- bole, quartz, and feldspathic matrix, without any accessory mineral.

Before experiment, the samples were cut into cylinders of $6 \mathrm{~mm}$ diameter and $6 \mathrm{~mm}$ height, and cleaned ultrasonically using deionized water, acetone, and ethanol in turn. Finally, they were placed in an oven at $323 \mathrm{~K}$ for $24 \mathrm{~h}$. The chemical composition and mineralogical proportion of the sample (Table 1) were analyzed by an X-ray fluorescence spectrometer (XRF) and an electron microprobe analysis (EPMA) at the State Key Laboratory of Ore Deposit Geochemistry, Institute of Geochemistry, Chinese Academy of Sciences, Guiyang, China.

\subsection{High-pressure conductivity cell and impedance measurements}

The electrical conductivity in situ measurements at high pressures and high temperatures were performed in a YJ-3000t multi-anvil apparatus and a Solartron-1260 Impedance/GainPhase Analyzer at the Key Laboratory of High-Temperature and High-Pressure Study of the Earth's Interior, Institute of Geochemistry, Chinese Academy of Sciences, Guiyang.

The equipment and experimental process are described in detail by Dai et al. (2012) and Hu et al. (2014). A diagram of the cross-section of the high-pressure cell assembly is shown in Fig. 1. In order to avoid the effect of dehydration on the impedance spectroscopy measurement, a pyrophyllite $(32.5 \times 32.5 \times 32.5 \mathrm{~mm})$ pressure-transmitting medium was heated at $1173 \mathrm{~K}$ for $12 \mathrm{~h}$ in a muffle furnace. The heater was composed of three-layer stainless steel sheets (total thickness: $0.5 \mathrm{~mm}$ ) in the shape of a tube. Similar to previous studies (Dai et al., 2012; Hu et al., 2014), an alumina and magnesia sleeve were used to ensure that the sample was in a relatively insulated environment. A grounded $0.025 \mathrm{~mm}$ thick nickel foil located in the middle of the alumina and magne- 


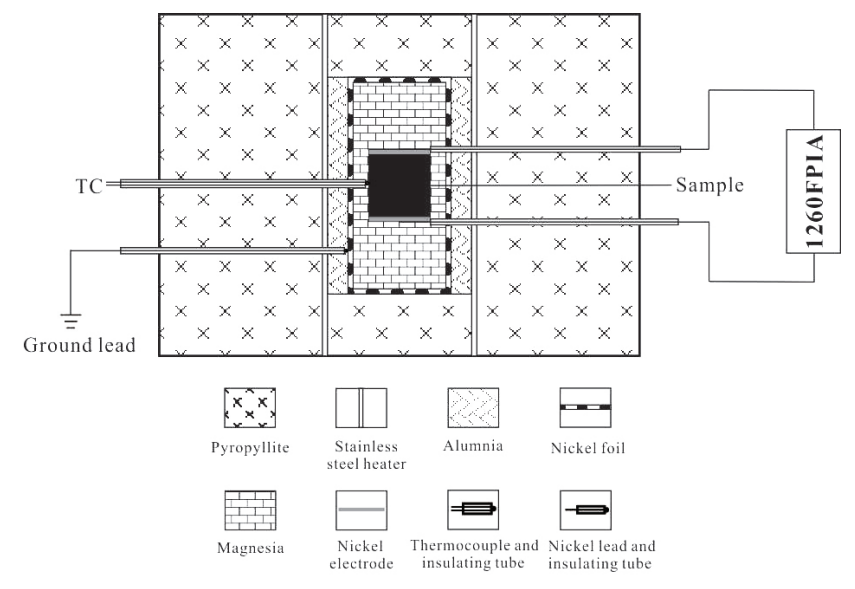

Figure 1. Experimental setup of electrical conductivity measurements.

sia sleeve shielded against external electromagnetic and spurious signal interference. The electrodes were composed of two nickel disks $(0.5 \mathrm{~mm}$ in thickness and $6 \mathrm{~mm}$ in diameter). Temperature was monitored using a $\mathrm{NiCr}-\mathrm{NiAl}$ thermocouple in contact with the middle of the sample.

During the experiment, a Solartron-1260 Impedance/GainPhase Analyzer was adopted to collect the impedance spectroscopy with a signal voltage of $1 \mathrm{~V}$ and frequency range of $10^{-1}-10^{6} \mathrm{~Hz}$. To explore the influence of pressure on electrical conductivity, electrical conductivity was conducted in the pressure range of $0.5-2.0 \mathrm{GPa}$. With pressure increased at $1.0 \mathrm{GPah}^{-1}$ to each designated pressure, sample was then heated at $100 \mathrm{~K} \mathrm{~h}^{-1}$, and the complex impedance of quartz andesite was measured at temperature intervals of $50 \mathrm{~K}$. To obtain credible data, the temperature was stabilized for several minutes at each step before measurement. Experimental errors in the temperature and pressure gradients during each measurement were no more than $\pm 10 \mathrm{~K}$ and $\pm 0.1 \mathrm{GPa}$, respectively. The obtained impedance spectra were fitted by an equivalent circuit made of a series of $R_{1}-C_{1}$ and $R_{2}-C_{2}-W$ ( $R_{1}$ and $C_{1}$ correspond respectively to the resistance and capacitance of grain interior conduction process, and $R_{2}, C_{2}$, and $W$ correspond respectively to the resistance, capacitance, and Warburg element of grain boundary conduction process).

\section{Experimental results}

In this study, the Nyquist and Bode plots, respectively, for the complex impedance of typical quartz andesite were obtained under conditions of $1.0 \mathrm{GPa}, 723-973 \mathrm{~K}$ and $10^{-1}$ $10^{6} \mathrm{~Hz}$ (Figs. 2 and 3). Similar results were also obtained under different pressures. The presence of different relaxation time constant led to the appearance in the Nyquist plot of both a semicircular arc and a $45^{\circ}$ slope in the complex impedance plane at the given frequency range. The first semicircle impedance arc $\left(10^{2}-10^{6} \mathrm{~Hz}\right)$ represents the grain in-

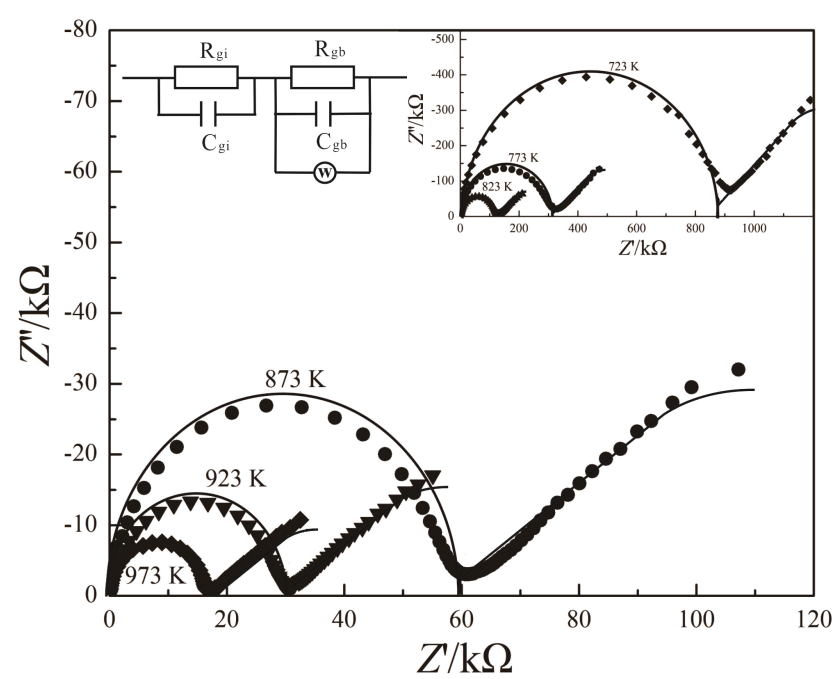

Figure 2. Nyquist plot of the complex impedance of quartz andesite under conditions of $1.0 \mathrm{GPa}$ and $723-973 \mathrm{~K}$.

terior conduction mechanism; it crosses the origin, and its center lies on the real axis. The $45^{\circ}$ slope in the complex impedance plane at the end of the first semicircle $\left(10^{-1}\right.$ $10^{2} \mathrm{~Hz}$ ) represents grain boundary diffusion. With the rise of temperature, the diameter of impedance arc and value of impedance decreased rapidly; hence, the electrical conductivity increased. The Bode plot (Fig. 3) reflects the dependence of modulus $(|Z|)$ and phase angle $(\theta)$ on frequency. From high to low frequency, the impedance modulus increased rapidly, and the absolute value of the phase angle tended toward zero. Impedance spectroscopy theory (Nover et al., 1992; Huebner and Dillenburg, 1995; Huang et al., $2005)$ relates the real part $\left(Z^{\prime}\right)$, imaginary part $\left(Z^{\prime \prime}\right)$, modulus $(|Z|)$ and phase angle $(\theta)$ as follows: $Z^{\prime}=|Z| \cos \theta$ and $Z^{\prime \prime}=|Z| \sin \theta$. According to previous studies (Dai and Karato, 2014a, b), the resistance of the grain interior can be determined by modeling the electrical response with equivalent circuit of resistance and capacitance $\left(R_{1} C_{1}\right)$. However, the impedance at low frequency is not wholly semicircular. By combing the $45^{\circ}$ of slope in the complex impedance at low frequency, a Warburg element was adopted to fit the grain boundary resistance. The equivalent circuit is shown in Fig. 2. Another equivalent circuit composed of a resistor and capacitor in parallel was used simultaneously to fit the total resistance. Furthermore, the grain interior, grain boundary and total electrical conductivity are in accordance with the following expression:

$\sigma=L / S R$

where $L$ is the sample length $(\mathrm{m}), S$ is the cross-sectional area of the electrode $\left(\mathrm{m}^{2}\right)$, and $R$ is the resistance for the given conduction process $(\Omega)$.

At pressures of $0.5-2.0 \mathrm{GPa}$ and temperatures of 723 $973 \mathrm{~K}$, the relationship between the electrical conductivity 


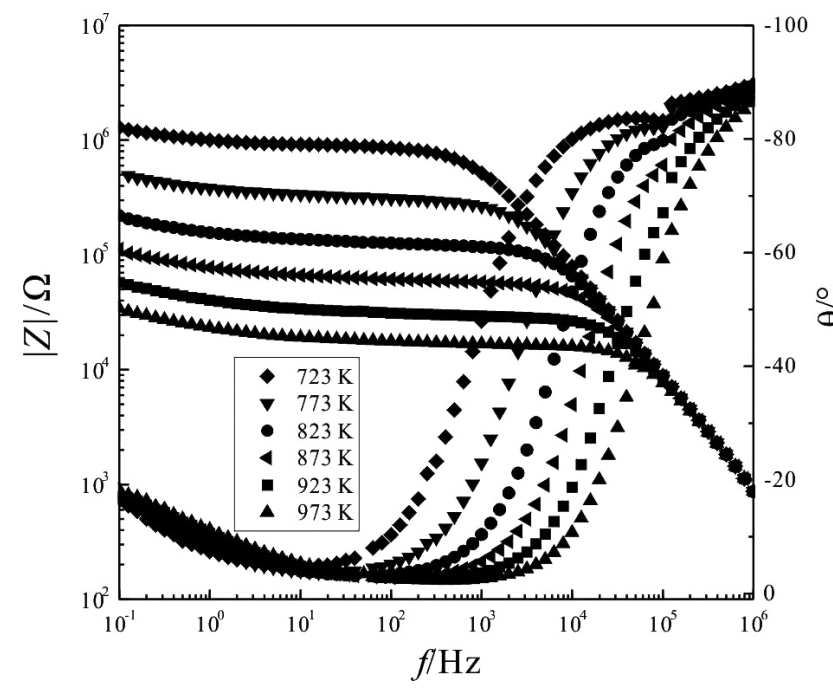

Figure 3. Bode plot of dependence of modulus and phase angle on frequency quartz andesite under conditions of $1.0 \mathrm{GPa}$ and 723 $973 \mathrm{~K}$.

$(\sigma)$ of the quartz andesite and reciprocal temperature $\left(T^{-1}\right)$ was fitted using the Arrhenius relation:

$\sigma=\sigma_{0} \exp (-\Delta H / k T)$

where $\sigma_{0}$ is the pre-exponential factor $\left(\mathrm{S} \mathrm{m}^{-1}\right), \Delta H$ is the activation enthalpy $(\mathrm{eV}), k$ is the Boltzmann constant, and $T$ is the absolute temperature (K). The relationship between activation energy $\Delta U(\mathrm{eV})$, pressure $P(\mathrm{GPa})$ and activation volume $\Delta V\left(\mathrm{~cm}^{3} \mathrm{~mol}^{-1}\right)$ is expressed as follows:

$\Delta H=\Delta U+P \times \Delta V$.

The grain interior, grain boundary, and total conductivity at different pressures and temperatures are plotted against reciprocal temperature in Figs. 4-6. Figures 4 and 5 show the plots for grain interior and grain boundary conductivity, respectively. The relationship between grain interior, grain boundary and total conductivity at $1.0 \mathrm{GPa}$ is shown in detail in Fig. 6, and the value of electrical conductivity under $1.0 \mathrm{GPa}$ is summarized in Table 2. Similar results were obtained under $0.5-2.0 \mathrm{GPa}$. The ratio of grain boundary $\left(\sigma_{\mathrm{gb}}\right)$ to grain interior $\left(\sigma_{\mathrm{gi}}\right)$ conductivity represents their respective contributions to total conductivity; it varies with temperature and pressure, and is plots in the range 0.5-2.0 GPa in Fig. 7 . Fitting parameters of the grain interior and grain boundary conductivity are listed in Table 3.

\section{Discussions}

In the present work, the grain interior $\left(\sigma_{\mathrm{gi}}\right)$, grain boundary $\left(\sigma_{\mathrm{gb}}\right)$ and total electrical conductivity $\left(\sigma_{\mathrm{t}}\right)$ of quartz andesite were measured in situ at the pressures of $0.5-2.0 \mathrm{GPa}$ and temperatures of $723-973 \mathrm{~K}$. With the rise of pressure, the

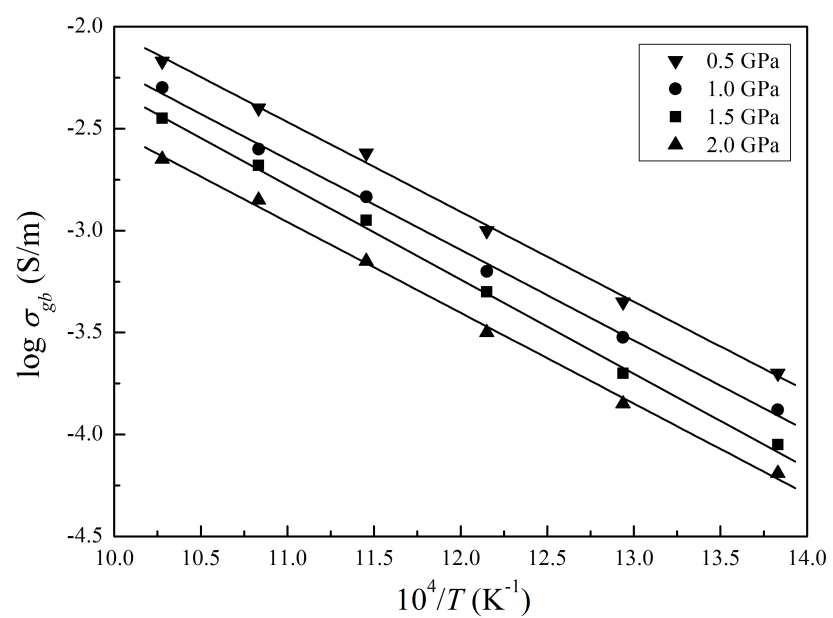

Figure 4. The relationship of the logarithmic grain boundary conductivity vs. reciprocal temperature under conditions of $0.5-$ 2.0 GPa and 723-973 K.

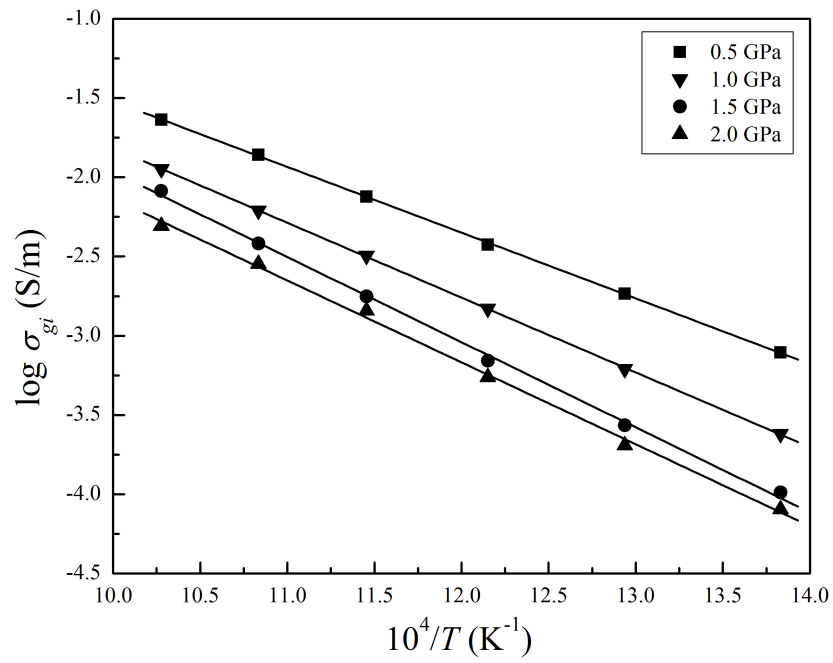

Figure 5. The relationship of the logarithmic grain interior conductivity vs. reciprocal temperature under conditions of $0.5-2.0 \mathrm{GPa}$ and $723-973 \mathrm{~K}$.

grain boundary conductivity decreases, while the activation enthalpy and pre-exponential factor increase (Fig. 4 and Table 3). From Fig. 6, it is clear that the grain boundary conductivity was higher than either the grain interior or total conductivity, and the total conductivity was lower than the grain interior conductivity.

The activation energy and activation volume for grain boundary conduction process under the experimental conditions were $0.90 \pm 0.10 \mathrm{eV}$ and $0.56 \pm 0.52 \mathrm{~cm}^{3} \mathrm{~mol}^{-1}$, respectively. The ratio of grain boundary to grain interior conductivity $\left(\sigma_{\mathrm{gb}} / \sigma_{\mathrm{gi}}\right)$ at $0.5-2.0 \mathrm{GPa}$ (Fig. 7) gradually decreased with increasing temperature and pressure; and thus the contribution of grain boundary conductivity to the total conductivity of quartz andesite continually decreased with 


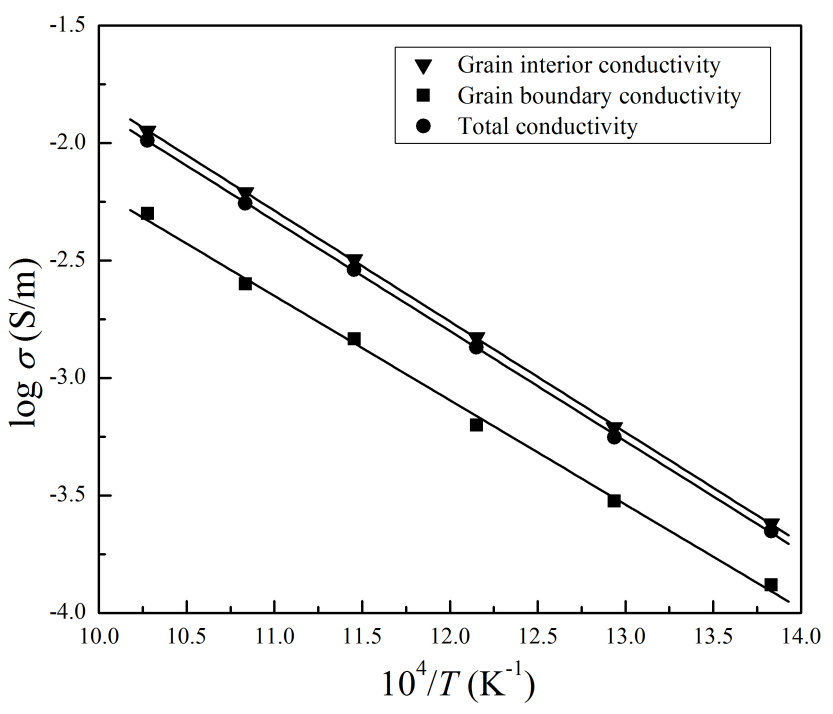

Figure 6. The relationship of grain interior, grain boundary and total conductivity under conditions of $1.0 \mathrm{GPa}$ and $723-973 \mathrm{~K}$.

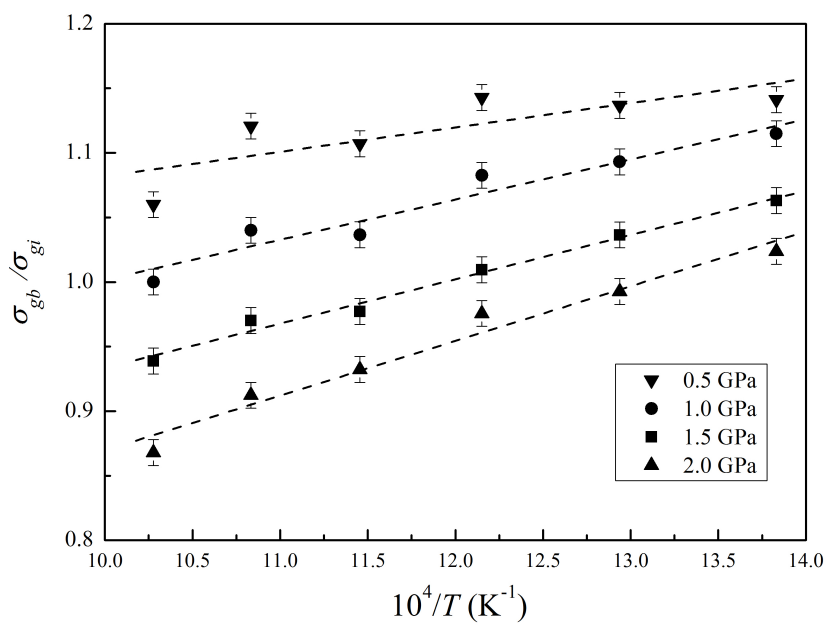

Figure 7. Grain boundary/grain interior conductivity $\left(\sigma_{\mathrm{gb}} / \sigma_{\mathrm{gi}}\right)$ versus reciprocal temperature $\left(T^{-1}\right)$ under conditions of $1.0 \mathrm{GPa}$ and $723-973 \mathrm{~K}$. The ratio represents the leading role of grain boundary or grain interior conductivity in the conduction process.

increasing temperature and pressure. Dai et al. (2008) presented a functional model of the variation of grain boundary conductivity with pressure in which the grain boundary conductivity of peridotite varies with the width of grain boundary, as follows:

$\sigma_{\mathrm{gb}-\mathrm{micro}}=\sigma_{\mathrm{gb}-\mathrm{bulk}}(d / D)$,

where $\sigma_{\mathrm{gb}-\mathrm{micro}}$ is the microscopic grain boundary conductivity $\left(\mathrm{S} \mathrm{m}^{-1}\right), \sigma_{\text {gb-bulk }}$ is the bulk grain boundary conductivity $\left(\mathrm{S} \mathrm{m}^{-1}\right), d$ is the grain boundary width $(\mu \mathrm{m})$, and $D$ is the grain size $(\mu \mathrm{m})$. According to Eq. (4), the diffusivity of cements between feldspar and amphibole in the quartz andesite
Table 2. The value of grain interior, grain boundary and total electrical conductivity under $1.0 \mathrm{GPa}$ and $723-973 \mathrm{~K}$. The estimate error for grain interior conductivity is lower than $5 \%$, for grain boundary conductivity is lower than $7 \%$, and for total conductivity is lower than $5 \%$.

\begin{tabular}{llll}
\hline & $\begin{array}{l}\log \sigma_{\mathrm{gi}} \\
\left(\mathrm{S} \mathrm{m}^{-1}\right)\end{array}$ & $\begin{array}{l}\log \sigma_{\mathrm{gb}} \\
\left(\mathrm{S} \mathrm{m}^{-1}\right)\end{array}$ & $\begin{array}{l}\log \sigma_{\mathrm{t}} \\
\left(\mathrm{S} \mathrm{m}^{-1}\right)\end{array}$ \\
\hline $723 \mathrm{~K}$ & -3.62 & -3.88 & -3.65 \\
$773 \mathrm{~K}$ & -3.21 & -3.52 & -3.25 \\
$823 \mathrm{~K}$ & -2.83 & -3.22 & -2.87 \\
$873 \mathrm{~K}$ & -2.50 & -2.83 & -2.539 \\
$923 \mathrm{~K}$ & -2.21 & -2.61 & -2.26 \\
$973 \mathrm{~K}$ & -1.95 & -2.29 & -1.99 \\
\hline
\end{tabular}

increased with the rise of pressure, reducing the grain boundary width along the direction of current transmission and decreasing the grain conductivity accordingly. These results are consistent with those of ten Grotenhuis et al. (2004) and Dai et al. (2008) on the effect of pressure on the grain boundary electrical conductivity of peridotite.

Figure 5 shows that the grain interior conductivity of the quartz andesite decreased with increasing pressure; the activation enthalpy and pre-exponential factor increased accordingly. The variation of grain interior conductivity with pressure observed here is similar to previous studies, which were concentrated on the effect of partially molten andesite (Waff and Weill, 1975; Tyburczy and Waff, 1983; Laumonier et al., 2015) (Fig. 8). The activation enthalpy (0.81-1.05 eV) and activation volume $\left(4.96 \pm 0.52 \mathrm{~cm}^{3} \mathrm{~mol}^{-1}\right)$ of quartz andesite are within the same range as results for andesite $(0.78$ $1.17 \mathrm{eV}$ and $3.25-17.9 \mathrm{~cm}^{3} \mathrm{~mol}^{-1}$, respectively) from Crater Lake (Tyburczy and Waff, 1983), and are also similar to those of dacitic melts $\left(0.69-1.0 \mathrm{eV}\right.$ and $3.9-24.7 \mathrm{~cm}^{3} \mathrm{~mol}^{-1}$, respectively) measured by Laumonier et al. (2015). However, discrepancies in pressure, temperature, melting conditions, and chemical composition of the samples are the important factors that might have led to 1-2 orders of magnitudes lower found here, compared with previous studies.

On the other hand, the logarithmic conductivity $(\log \sigma)$ and reciprocal temperature $\left(T^{-1}\right)$ show a strong linear relationship (>99\%). On the base of the result, including $\mathrm{FeO}=5.02 \mathrm{wt} \%$ in the quartz andesite (Table 1), $\Delta H=$ $0.81-1.05 \mathrm{eV}$ and $\Delta V=4.96 \pm 0.52 \mathrm{~cm}^{3} \mathrm{~mol}^{-1}$ (Table 3); this implies that there is only one single dominant conduction mechanism for quartz andesite. Numerous studies have reported similar results, indicating that the conduction mechanism is the small polaron (Xu et al., 1998; Scarlato et al., 2004; Dai et al., 2008; Yang and Heidelbach, 2011). We consider that the conduction mechanism of grain interior conduction process is the small polaron conduction. The hopping process can be described as follows:

$\mathrm{Fe}_{\mathrm{Mg}}^{x}+h^{\bullet} \rightleftharpoons \mathrm{Fe}_{\mathrm{Mg}}^{\cdot}$. 
Table 3. Fitted parameters for the grain interior and grain boundary conductivity of quartz andesite.

\begin{tabular}{lccccccc}
\hline & $P(\mathrm{GPa})$ & $T(\mathrm{~K})$ & $\log \sigma_{0}\left(\mathrm{~S} \mathrm{~m}^{-1}\right)$ & $\Delta H(\mathrm{eV})$ & $\gamma^{2}$ & $\Delta U(\mathrm{eV})$ & $\Delta V\left(\mathrm{~cm}^{3} \mathrm{~mol}^{-1}\right)$ \\
\hline Grain boundary & 0.5 & $723-973$ & $2.36 \pm 0.13$ & $0.87 \pm 0.02$ & 99.67 & $0.90 \pm 0.10$ & $0.56 \pm 0.52$ \\
& 1.0 & $723-973$ & $2.24 \pm 0.13$ & $0.88 \pm 0.02$ & 99.70 & & \\
& 1.5 & $723-973$ & $2.30 \pm 0.11$ & $0.92 \pm 0.02$ & 99.78 & & \\
\hline Grain interior & 2.0 & $723-973$ & $1.94 \pm 0.12$ & $0.89 \pm 0.02$ & 99.71 & & $4.96 \pm 0.52$ \\
& 0.5 & $723-973$ & $1.63 \pm 0.03$ & $0.81 \pm 0.01$ & 99.97 & $0.76 \pm 0.06$ & \\
& 1.0 & $723-973$ & $1.90 \pm 0.02$ & $0.93 \pm 0.01$ & 99.99 & & \\
& 1.5 & $723-973$ & $2.41 \pm 0.01$ & $1.05 \pm 0.02$ & 99.81 & & \\
& 2.0 & $723-973$ & $2.03 \pm 0.01$ & $1.02 \pm 0.03$ & 99.70 & & \\
\hline
\end{tabular}

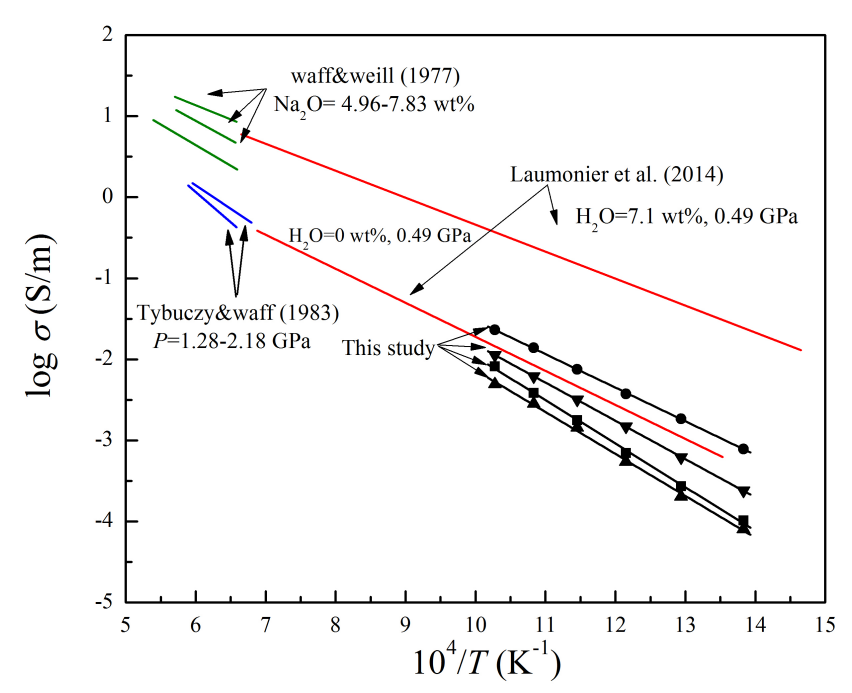

Figure 8. A comparison of grain interior conductivity of quartz andesite with previous studies.

In ferromagnesian silicate, the presence of $\mathrm{Fe}_{\mathrm{Mg}}^{\cdot}$ generates an extra positive charge that repulses cations, causing the lattice deformation is a small polaron (Dai et al., 2013). The small polaron is an important conduction mechanism at low temperature; it is characterized by the transfer of an electron hole $\left(h^{\bullet}\right)$ from $\mathrm{Fe}_{\mathrm{Mg}}^{\cdot}$ to $\mathrm{Fe}_{\mathrm{Mg}}^{x}$ (Schmidbauer et al., 2000; Huang et al., 2005; Poe et al., 2008; Dai et al., 2014, 2015). In light of the above-mentioned results, the low energy barrier for the transmission process resulted in the low activation enthalpy of quartz andesite. Two further factors, oxygen fugacity and iron content, also affect the small polaron conduction of quartz andesite. The proportion of ferric iron in the total iron $\left(\mathrm{Fe}^{3+} / \Sigma \mathrm{Fe}\right)$ increases with increasing oxygen fugacity; with the rise of iron content, the charge carrier concentration also increases. However, understanding the effects of oxygen fugacity and iron content on the grain interior conductivity of quartz andesite requires further research.

As mentioned above, a Warburg element was adopted to fit the grain boundary resistance; and it indicates that the grain boundary conduction process occurred via ion diffusion. A large quantity of alkali ions are contained in the quartz andesite $\left(\mathrm{Na}_{2} \mathrm{O}: 4.98 \mathrm{wt} \% ; \mathrm{K}_{2} \mathrm{O}: 4.16 \mathrm{wt} \%\right)$, and requires only low activation energy (Hu et al., 2014). Combing the activation energy of the grain boundary conduction process $(0.87$ $0.92 \mathrm{eV}$ ), we conclude that the grain boundary conduction mechanism for quartz andesite is the ion conduction. However, understanding the effects of alkali ion content on the grain boundary conductivity of quartz andesite requires further research.

\section{Conclusions}

At pressures of $0.5-2.0 \mathrm{GPa}$ and temperatures of 723-973 K, and within the frequency $10^{-1}-10^{6} \mathrm{~Hz}$, the grain boundary conductivity of quartz andesite ranged from $10^{-4.2}$ to $10^{-2.2} \mathrm{~S} \mathrm{~m}^{-1}$; the activation enthalpy and activation volume were $0.87-0.92 \mathrm{eV}$ and $0.56 \pm 0.52 \mathrm{~cm}^{3} \mathrm{~mol}^{-1}$, respectively. The grain boundary conductivity varied greatly with pressure, temperature. Its effect on the total conductivity increased with the rise of temperature. The grain boundary conductivity tended to decrease with increasing pressure. At 0.5 $2.0 \mathrm{GPa}$, the total conductivity of quartz andesite is slightly lower than grain interior conductivity due to the presence of grain boundary. These obtained physical parameters, combined with data on the chemical and mineralogical composition of the andesite, suggest that the conduction mechanism for grain interior of quartz andesite is the small polaron conduction, and for grain boundary is the ion conduction.

Acknowledgements. We thank the editor Juan Carlos Afonso and two reviewers (Nover Georg and Clark Simon) for their very constructive comments and suggestions during the reviewing process, which helped us greatly in improving the manuscript. This research was financially supported by the " 135 " Program of Institute of Geochemistry of CAS, Hundred Talents Program of CAS, Youth Innovation Promotion Association of CAS and NSF of China (41474078, 41304068 and 41174079).

Edited by: J. C. Afonso 


\section{References}

Dai, L. D. and Karato, S.: Influence of $\mathrm{FeO}$ and $\mathrm{H}$ on the electrical conductivity of olivine, Phys. Earth Planet. In., 237, 73-79, 2014a.

Dai, L. D. and Karato, S.: High and highly anisotropic electrical conductivity of the asthenosphere due to hydrogen diffusion in olivine, Earth Planet Sci. Lett., 408, 79-86, 2014b.

Dai, L. D., Li, H. P., Hu, H. Y., and Shan, S. M.: Experimental study of grain boundary electrical conductivities of dry synthetic peridotite under high-temperature, high-pressure, and different oxygen fugacity conditions, J. Geophys. Res., 113, B12211, doi:10.1029/2008jb005820, 2008.

Dai, L. D., Li, H. P., Hu, H. Y., Shan, S. M., Jiang, J. J., and Hui, K. S.: The effect of chemical composition and oxygen fugacity on the electrical conductivity of dry and hydrous garnet at high temperatures and pressures, Contrib. Mineral. Petrol., 163, 689700, 2012

Dai, L., Li, H. P., Hu, H. Y., Jiang, J. J., Hui, K. S., and Shan, S. M.: Electrical conductivity of $\mathrm{Alm}_{82} \mathrm{Py}_{15} \mathrm{Grs}_{3}$ almandine-rich garnet determined by impedance spectroscopy at high temperatures and high pressures, Tectonophysics, 608, 1086-1093, 2013.

Dai, L. D., Hu, H. Y., Li, H. P., Jiang, J. J., and Hui, K. S.: Influence of temperature, pressure, and chemical composition on the electrical conductivity of granite, Am. Mineral., 99, 1420-1428, 2014.

Dai, L. D., Li, H. P., Hu, H. Y., Hui, K. S., Jiang, J. J., Li, J., and Sun, W. Q.: Electrical conductivity of gabbro: the effect of temperature, pressure and oxygen fugacity, Eur. J. Mineral., 27, 215-224, 2015.

Hu, H. Y., Dai, L. D., Li, H. P., Jiang, J. J., and Hui, K. S.: Electrical conductivity of K-feldspar at high temperature and high pressure, Miner. Petrol., 108, 609-618, 2014.

Huang, X. G., Xu, Y. S., and Karato, S.: Water content in the transition zone from electrical conductivity of wadsleyite and ringwoodite, Nature, 434, 746-749, 2005.

Huebner, J. S. and Dillenburg, R. G.: Impedance spectra of hot, dry silicate minerals and rock-qualitative interpretation of spectra, Am. Mineral., 80, 46-64, 1995.

Laumonier, M., Gaillard, F., and Sifre, D.: The effect of pressure and water concentration on the electrical conductivity of dacitic melts: implication for magnetotelluric imaging in subduction areas, Chem. Geol., doi:10.1016/j.chemgeo.2014.09.019, in press, 2015.

Nover, G., Will, G., and Waitz, R.: Pressure-induced phasetransition in $\mathrm{Mg}_{2} \mathrm{GeO}_{4}$ as determined by frequency-dependent complex electrical-resistivity measurements, Phys. Chem. Miner., 19, 133-139, 1992.

Poe, B. T., Romano, C., Varchi, V., Misiti, V., and Scarlato, P. : Electrical conductivity of a phonotephrite from Mt. Vesuvius: The importance of chemical composition on the electrical conductivity of silicate melts, Chem. Geol., 256, 193-202, 2008.
Roberts, J. J. and Tyburczy, J. A.: Frequency dependent electrical properties of polycrystalline olivine compacts, J. Geophys. Res., 96, 16205-16222, 1991.

Roberts, J. J. and Tyburczy, J. A.: Frequency-dependent electricalproperties of dunite as functions of temperature and oxygen fugacity, Phys. Chem. Miner., 19, 545-561, 1993.

Roberts, J. J. and Tyburczy, J. A.: Frequency-dependent electricalproperties of minerals and partial-melts, Surv. Geophys, 15, 239262, 1994.

Scarlato, P., Poe, B. T., and Freda, C.: High-pressure and hightemperature measurements of electrical conductivity in basaltic rocks from Mount Etna, Sicily, Italy, J. Geophys. Res., 109, 210 220, 2004.

Schmidbauer, E., Kunzmann, T., Fehr, T., and Hochleitner, R.: Electrical resistivity and Fe-57 Mossbauer spectra of Fe-bearing calcic amphiboles, Phys. Chem. Miner., 27, 347-356, 2000.

ten Grotenhuis, S. M., Drury, M. R., Peach, C. J., and Spiers, C. J.: Electrical properties of fine-grained olivine: Evidence for grain boundary transport, J. Geophys. Res., 109, B06203, doi:10.1029/2003jb002799, 2004.

Tyburczy, J. A. and Roberts, J. J.: Low frequency electrical response of polycrystalline olivine compacts: grain boundary transport, Geophys. Res. Lett., 17, 1985-1988, 1990.

Tyburczy, J. A. and Waff, H. S.: Electrical conductivity of molten basalt and andesite to 25 kilobars pressure: Geophysical significance and implications for charge transport and melt structure, J. Geophys. Res., 88, 2413-2430, 1983.

Waff, H. S. and Weill, D. F.: Electrical conductivity of magmatic liquids effects of temperature: effects of temperature, oxygen fugacity and composition, Earth Planet Sc. Lett., 28, 254-260, 1975.

Watson, H. C., Roberts, J. J., and Tyburczy, J. A.: Effect of conductive impurities on electrical conductivity in polycrystalline olivine, Geophys. Res. Lett., 37, L02302, doi:10.1029/2009g1041566, 2010.

Wu, X. P., Zhang, B. H., Xu, J. S., Katsura, T., Zhai, S. M., Yoshino, T., Manthilake, G., and Shatskiy, A.: Electrical conductivity measurements of periclase under high pressure and high temperature, Phys. B, 405, 53-56, 2010.

Xu, Y. S., Poe, B. T., Shankland, T. J., and Rubie, D. C.: Electrical conductivity of olivine, wadsleyite, and ringwoodite under upper-Mantle conditions, Science, 280, 5368, 1415-1418, 1998.

$\mathrm{Xu}$, Y. S., Shankland, T. J., and Duba, A. G.: Pressure effect on electrical conductivity of mantle olivine, Phys. Earth Planet. In., 118, 149-161, 2000.

Yang, X. Z. and Heidelbach, F.: Grain size on the electrical conductivity of clinopyroxene, Contrib. Mineral. Petrol., 163, 939-947, 2011. 